\title{
Male breast cancer: A retrospective study comparing survival with female breast cancer
}

\author{
LI BAOJIANG ${ }^{1}$, LIU TINGTING $^{1}$, LI GANG $^{2}$ and ZHANG LI $^{3}$ \\ ${ }^{1}$ Department of Breast Oncology and ${ }^{2}$ Vascular Surgery, The Central Hospital of Tai'an, Tai'an, Shandong 271000; \\ ${ }^{3}$ Department of Breast Oncology, Key Laboratory of Breast Cancer Prevention and Therapy, \\ Tianjin Medical University Cancer Institute and Hospital, Ministry of Education, Tianjin 300060, P.R. China
}

Received February 22, 2012; Accepted June 7, 2012

DOI: $10.3892 / \mathrm{ol} .2012 .809$

\begin{abstract}
Male breast cancer is a rare disease. The aim of this study was to compare overall survival (OS) and disease-free survival (DFS) in a group of matched males and females with breast cancer. The clinical data and survival status of 42 operable male breast cancer (MBC) cases treated at the Central Hospital of Tai'an from 1982 to 2006 were collected. Each MBC patient recorded in the database was matched with two female breast cancer (FBC) patients. Matching was conducted based on age, year of diagnosis, stage and pathology. SPSS 16.0 software was used for statistical analysis. The Chi-square test was used for the categorical data, the Kaplan-Meier method was applied to analyze survival and the log-rank test was used to compare curves between the groups. $\mathrm{P}<0.05$ was considered to indicate a statistically significant difference. The $42 \mathrm{MBC}$ patients were matched with $84 \mathrm{FBC}$ patients. The mean age at diagnosis was $58.0 \pm 11.3$ years for males and $57.1 \pm 10.6$ years for females, and the median follow-up time was 64 months (range, 5-262 months) for males and 71 months (range, 29-283 months) for females. Significant differences were identified for tumor location, hormone receptor status, adjuvant chemotherapy and hormone therapy between the two groups. Monofactorial analysis demonstrated that tumor size, lymph node status and AJCC stage were prognostic factors in MBC patients. The 5- and 10-year DFS rates were 61.2 and $40.7 \%$ for males, and 68.7 and $43.0 \%$ for females, respectively. The 5and 10-year OS rates were 75.3 and $52.3 \%$ for males, and 82.9 and $63.2 \%$ for females, respectively. In our study, male breast carcinoma patients had a worse prognosis compared to female breast carcinoma patients which may be due to the deficiency of adjuvant chemotherapy and endocrine therapy.
\end{abstract}

Correspondence to: $\mathrm{Dr} \mathrm{Li}$ Baojiang, Department of Breast Oncology, The Central Hospital of Tai'an, 29 Longtan Road, Tai'an, Shandong 271000, P.R. China

E-mail: libaojiang8052@126.com

Key words: male breast cancer, female breast cancer, clinical characteristics, therapy, prognosis

\section{Introduction}

Male breast cancer (MBC) accounts for less than $1 \%$ of all types of cancer in males (1). Due to its rarity, there have been no prospective randomized clinical trials of MBC patients (2). Clinical management of MBC is guided by research on the disease in females or by data from small case studies. Due to its low incidence, a limited number of patients are collected for this study.

Recent studies have been conducted with regard to MBC survival in comparison with female breast cancer (FBC); however, no MBC study has been reported in Chinese patients. It was considered that $\mathrm{MBC}$ had a worse prognosis compared to FBC (3), but recent retrospective studies revealed that $\mathrm{MBC}$ and $\mathrm{FBC}$ patients have a similar prognosis $(4,5)$. In view of this discrepancy, we compared the disease-free survival (DFS) and overall survival (OS) in a group of carefully matched MBC and FBC patients in a Chinese population.

\section{Patients and methods}

Patients and methods. Data for our study were obtained retrospectively from the breast cancer database at the Department of Breast Oncology, The Central Hospital of Tai'an (Central Hospital of Taishan Medical College), China. To protect patient confidentiality, we collected only coded data without direct patient identifiers. Each male with invasive breast cancer diagnosed between September 1982 and December 2006 was recorded in the database and carefully matched with two females. Inclusion criteria of MBC for our study included availability of well-documented clinical information and availability of accurate TNM stage, stages I-III. Exclusion criteria for the study included patients with carcinoma in situ or with history of other tumors, presence of metastatic lesions at initial diagnosis and patients who were operated in other institutions. Matching criteria included pathology of invasive ductal carcinoma in MBC and FBC, age at diagnosis ( \pm 5 years), year of diagnosis $( \pm 5$ years) $(6,7)$ and identical stage of the primary cancer at diagnosis. The females were selected from a total of 5,964 consecutive patients whose data were recorded in the same database and who underwent treatment at our institution during the same period. When more than two females met the 
Table I. Characteristics of patients with breast carcinoma.

\begin{tabular}{|c|c|c|}
\hline Characteristics & $\begin{array}{c}\mathrm{MBC}, \mathrm{n}=42 \\
(\%)\end{array}$ & $\begin{array}{c}\mathrm{FBC}, \mathrm{n}=84 \\
(\%)\end{array}$ \\
\hline \multicolumn{3}{|l|}{ Age at diagnosis (years) } \\
\hline Mean \pm SD & $58.0 \pm 11.3$ & $57.1 \pm 10.6$ \\
\hline Median (range) & $60(26-75)$ & $58(22-76)$ \\
\hline \multicolumn{3}{|l|}{ Year of diagnosis } \\
\hline 1982-1989 & $7(16.7)$ & $14(16.7)$ \\
\hline 1990-1999 & $18(42.8)$ & $36(42.8)$ \\
\hline 2000-2006 & $17(40.5)$ & $34(40.5)$ \\
\hline \multicolumn{3}{|l|}{ Follow-up time (months) } \\
\hline Mean $\pm \mathrm{SD}$ & $74.2 \pm 49.3$ & $86.8 \pm 49.2$ \\
\hline Median (range) & $64(5-262)$ & $71(29-283)$ \\
\hline \multicolumn{3}{|l|}{ AJCC stage } \\
\hline I & $6(14.3)$ & $12(14.3)$ \\
\hline II & $24(57.1)$ & $48(57.1)$ \\
\hline III & $12(28.6)$ & $24(28.6)$ \\
\hline \multicolumn{3}{|l|}{ Recurrence during follow-up } \\
\hline No & $22(52.4)$ & $49(58.3)$ \\
\hline Yes & $20(47.6)$ & $35(41.7)$ \\
\hline \multicolumn{3}{|l|}{ Status at end of follow-up } \\
\hline Alive & $20(47.6)$ & $48(57.1)$ \\
\hline Dead & $22(52.4)$ & $36(42.9)$ \\
\hline \multicolumn{3}{|l|}{ Cause of mortality } \\
\hline Breast cancer & $12(54.6)$ & $26(72.2)$ \\
\hline Complication of treatment & $1(4.5)$ & $0(0)$ \\
\hline Contralateral breast cancer & $1(4.5)$ & $1(2.8)$ \\
\hline Another cancer & $5(22.7)$ & $2(5.6)$ \\
\hline Another disease & $3(13.7)$ & $7(19.4)$ \\
\hline
\end{tabular}

MBC, male breast cancer; FBC, female breast cancer. SD, standard deviation; AJCC, American Joint Committee on Cancer.

criteria for matching, the female patients whose date of diagnosis was closer to the male patient's date of diagnosis were selected (4). A total of $42 \mathrm{MBC}$ patients and 84 matched FBC patients were enrolled in the study.

Potential prognostic factors included for each case were: elements of American Joint Committee on Cancer (AJCC) stage (TNM), Scarff-Bloom-Richardson (SBR) tumor grade, age at diagnosis, year of diagnosis, histological type, estrogen receptor $(\mathrm{ER})$ and progesterone receptor $(\mathrm{PR})$ status, laterality and tumor location.

Statistical analysis. To compare the breast cancer characteristics between males and females, the Chi-square test was used for categorical data and the Student's t-test for continuous data. The median length of follow-up was calculated using the inverse Kaplan-Meier method (8), and DFS and OS were calculated using Kaplan-Meier methods (9). A survival analysis was performed on the data set including all cases diagnosed between January 1, 1982 and December 31, 2006 with follow-up until March 1, 2011. Statistical analysis was

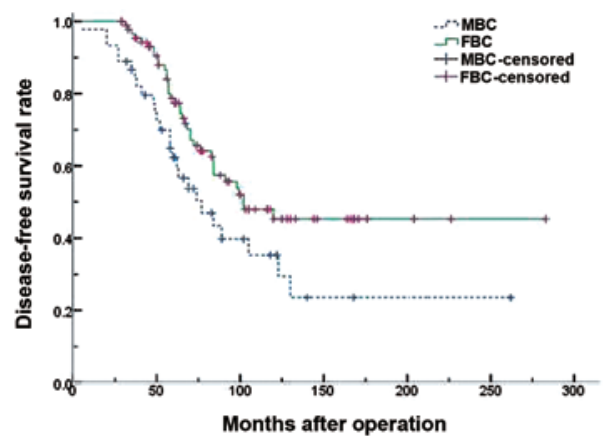

Figure 1. Comparison of disease-free survival time between $\mathrm{MBC}$ and $\mathrm{FBC}$ patients $(\mathrm{P}=0.043)$. $\mathrm{MBC}$, male breast cancer; $\mathrm{FBC}$, female breast cancer.

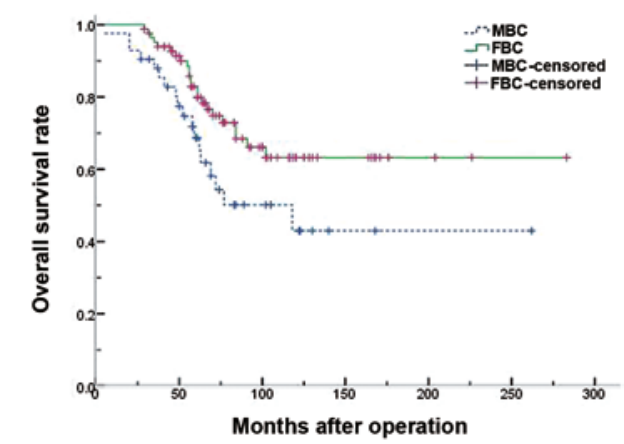

Figure 2. Comparison of overall survival between $\mathrm{MBC}$ and $\mathrm{FBC}$ patients $(\mathrm{P}=0.037)$. $\mathrm{MBC}$, male breast cancer; $\mathrm{FBC}$, female breast cancer.

performed using SPSS 16.0 for Windows and $\mathrm{P}<0.05$ was considered to indicate a statistically significant difference.

\section{Results}

The $42 \mathrm{MBC}$ patients were matched to 84 FBC patients during the same period. Table I demonstrates the matching information and demographic data of the matched male and female breast cancer patients. The mean age at diagnosis was similar for the two matched groups; 58.0 \pm 11.3 years (range, 26-75 years) for males and 57.1 \pm 10.6 years (range, 22-76 years) for females. The mean follow-up time for the 25 -year study period was 74.2 \pm 49.3 months (range, 5-262 months) for males and 86.8 \pm 49.2 months (range, 29-283 months) for females. Invasive ductal carcinoma was the pathological type of all cases.

Significant differences were identified for tumor location $(\mathrm{P}<0.01)$, hormone receptor status $(\mathrm{P}=0.018)$, adjuvant chemotherapy $(\mathrm{P}=0.041)$ and hormone therapy $(\mathrm{P}=0.010)$ between male and female patients (Table II). Males were more likely to have an unknown tumor receptor status (26.2\%) compared to females $(14.3 \%)$. Stage-specific treatment and use of multimodality therapy (surgery and radiotherapy) did not differ between the two matched groups.

Univariate analysis revealed that tumor size, lymph node state and AJCC stage were significant prognostic factors of MBC $(\mathrm{P}<0.05)$ (Table III). Figs. 1 and 2 demonstrate the survival results of the two groups. The 5- and 10-year DFS rates were 61.2 and $40.7 \%$ for males, and 75.3 and $52.3 \%$ for females, respectively, which was significantly different 
Table II. Comparison of characteristics between MBC and FBC patients.

\begin{tabular}{|c|c|c|c|c|}
\hline Characteristics & $\begin{array}{c}\mathrm{MBC} \mathrm{n}=42 \\
(\%)\end{array}$ & $\begin{array}{c}\mathrm{FBC} n=84 \\
(\%)\end{array}$ & $\chi^{2}$ & P-value \\
\hline \multicolumn{5}{|l|}{ Laterality } \\
\hline Right & $20(47.6)$ & $43(51.2)$ & & \\
\hline Left & $22(52.4)$ & $41(48.8)$ & 0.143 & 0.705 \\
\hline \multicolumn{5}{|l|}{ Tumor location } \\
\hline Central & $14(33.3)$ & $3(3.6)$ & & \\
\hline Peripheral quadrant & $28(66.7)$ & $81(96.4)$ & 21.249 & $0.000^{\mathrm{a}}$ \\
\hline \multicolumn{5}{|l|}{ SBR tumor grade } \\
\hline 1 & $9(21.4)$ & $11(13.1)$ & & \\
\hline 2 & $27(64.3)$ & $63(75.0)$ & & \\
\hline 3 & $6(14.3)$ & $10(11.9)$ & 1.800 & 0.407 \\
\hline \multicolumn{5}{|l|}{ Tumor size } \\
\hline$\leq 5 \mathrm{~cm}$ & $35(83.3)$ & $69(82.1)$ & & \\
\hline$>5 \mathrm{~cm}$ & 7 (16.7) & $15(17.9)$ & 0.028 & 0.868 \\
\hline \multicolumn{5}{|l|}{ Lymph node status } \\
\hline Negative & $23(54.8)$ & $39(46.4)$ & & \\
\hline Positive & $19(45.2)$ & $45(53.6)$ & 0.778 & 0.378 \\
\hline \multicolumn{5}{|l|}{ Hormone receptor } \\
\hline ER- and/or PR-positive & $28(66.7)$ & $49(58.3)$ & & \\
\hline ER- and/or PR-negative & $3(7.1)$ & $23(27.4)$ & & \\
\hline Unknown & $11(26.2)$ & $12(14.3)$ & 8.050 & $0.018^{\mathrm{a}}$ \\
\hline \multicolumn{5}{|l|}{ Surgical procedure } \\
\hline Radical mastectomy & $40(95.2)$ & $82(97.6)$ & & \\
\hline Modified radical mastectomy & $2(1.3)$ & $2(2.7)$ & 0.032 & 0.857 \\
\hline \multicolumn{5}{|l|}{ Adjuvant chemotherapy } \\
\hline No & $18(42.9)$ & $21(25.0)$ & & \\
\hline Yes & $24(57.1)$ & $63(75.0)$ & 4.178 & $0.041^{\mathrm{a}}$ \\
\hline \multicolumn{5}{|l|}{ Radiotherapy } \\
\hline No & $25(59.5)$ & $46(54.8)$ & & \\
\hline Yes & $17(40.5)$ & $38(45.2)$ & 0.258 & 0.611 \\
\hline \multicolumn{5}{|l|}{ Hormone therapy } \\
\hline No & $32(76.2)$ & $44(52.4)$ & & \\
\hline Yes & $10(23.8)$ & $40(47.6)$ & 6.632 & $0.010^{\mathrm{a}}$ \\
\hline
\end{tabular}

${ }^{a} \mathrm{P}<0.05$. MBC, male breast cancer; FBC, female breast cancer. SBR, Scarff-Bloom-Richardson; ER, estrogen receptor; PR, progesterone receptor.

$(\mathrm{P}=0.043)$ (Table IV). The 5- and 10-year OS rates were 68.7 and $43.0 \%$ for males, and 82.9 and $63.2 \%$ for females, respectively, which was also significantly different $(\mathrm{P}=0.037)$.

\section{Discussion}

$\mathrm{MBC}$ is a rare disease, but the incidence is increasing, with a reported 26\% increase in the USA between 1973 and 1998 (10). The poor prognosis for MBC has been attributed to the advanced stage at presentation due to the lack of awareness and high incidence of lymph node metastases $(11,12)$. However, recent studies have demonstrated that if $\mathrm{MBC}$ patients are matched for prognostic factors, including age and TNM stage, the clinical outcome is similar $(4,13)$.
Following successful matching, we compared the survival of MBC and FBC patients. We analyzed potential prognostic factors prior to prognosis analysis and identified that the two groups were comparable. The matching criteria of this study included similar age at diagnosis, similar time of diagnosis, identical stage and identical pathology. Upon investigation of the characteristics of all patients, we revealed that the tumor location was different. Compared to female patients, more male patients had centrally located tumors (33.3 vs. 3.6\%), and the difference was significant $(\mathrm{P}<0.001)$. We also compared the estrogen receptor and progesterone receptor (ER/PR) status between the two groups. Expression levels of ER/PR were higher in MBC patients compared to FBC patients (14). Due to the long time span of this study and the late development of 
Table III. Monofactorial analysis of prognosis in MBC patients.

\begin{tabular}{|c|c|c|c|c|c|c|c|}
\hline \multirow[b]{2}{*}{ Characteristics } & \multirow[b]{2}{*}{$\mathrm{N}$} & \multicolumn{3}{|c|}{ DFS } & \multicolumn{3}{|c|}{ OS } \\
\hline & & 5 -year \% & $\chi^{2}$ & P-value & 5 -year \% & $\chi^{2}$ & P-value \\
\hline \multicolumn{8}{|l|}{ Age (years) } \\
\hline$<60$ & 20 & 62.7 & & & 76.1 & & \\
\hline$\geq 60$ & 22 & 58.7 & 2.058 & 0.151 & 71.9 & 3.309 & 0.129 \\
\hline \multicolumn{8}{|l|}{ Tumor size } \\
\hline$\leq 5 \mathrm{~cm}$ & 35 & 64.4 & & & 81.1 & & \\
\hline$>5 \mathrm{~cm}$ & 7 & 14.3 & 9.033 & $0.003^{\mathrm{a}}$ & 38.1 & 8.006 & $0.005^{\mathrm{a}}$ \\
\hline \multicolumn{8}{|c|}{ Lymph node status } \\
\hline Negative & 23 & 69.3 & & & 86.5 & & \\
\hline Positive & 19 & 28.9 & 4.639 & $0.031^{\mathrm{a}}$ & 56.5 & 7.256 & $0.007^{\mathrm{a}}$ \\
\hline \multicolumn{8}{|l|}{ AJCC stage } \\
\hline $\mathrm{I}+\mathrm{II}$ & 30 & 71.1 & & & 92.6 & & \\
\hline III & 12 & 8.3 & 30.189 & $0.000^{\mathrm{a}}$ & 22.9 & 25.967 & $0.000^{2}$ \\
\hline \multicolumn{8}{|c|}{ Adjuvant chemotherapy } \\
\hline No & 18 & 48.5 & & & 57.9 & & \\
\hline Yes & 24 & 56.1 & 2.126 & 0.145 & 86.8 & 2.251 & 0.134 \\
\hline \multicolumn{8}{|l|}{ Radiotherapy } \\
\hline No & 25 & 51.7 & & & 70.6 & & \\
\hline Yes & 17 & 53.6 & 0.012 & 0.912 & 80.9 & 1.434 & 0.231 \\
\hline \multicolumn{8}{|c|}{ Hormone therapy } \\
\hline No & 32 & 49.0 & & & 75.8 & & \\
\hline Yes & 10 & 63.6 & 0.004 & 0.947 & 68.2 & 0.103 & 0.748 \\
\hline
\end{tabular}

${ }^{\mathrm{a}} \mathrm{P}<0.05$. MBC, male breast cancer. DFS, disease-free survival; OS, overall survival. AJCC, American Joint Committee on Cancer.

Table IV. Comparison of survival between MBC and FBC patients.

\begin{tabular}{|c|c|c|c|c|c|c|c|c|}
\hline \multirow{2}{*}{$\begin{array}{l}\text { Survival } \\
\text { rate } \\
\text { (years) }\end{array}$} & \multicolumn{4}{|c|}{ DFS } & \multicolumn{4}{|c|}{ OS } \\
\hline & MBC \% & FBC $\%$ & $\chi^{2}$ & P-value & $\mathrm{MBC} \%$ & FBC $\%$ & $\chi^{2}$ & P-value \\
\hline 5 & 61.2 & 75.3 & & & 68.7 & 82.9 & & \\
\hline 10 & 40.7 & 52.3 & 4.113 & $0.043^{\mathrm{a}}$ & 43.0 & 63.2 & 4.331 & $0.037^{\mathrm{a}}$ \\
\hline
\end{tabular}

${ }^{\mathrm{a}} \mathrm{P}<0.05$. MBC, male breast cancer; FBC, female breast cancer. DFS, disease-free survival; OS, overall survival.

c-erbB-2 detection methods in 2003, the patients with c-erbB-2 detection were few (11 MBC patients, 36 FBC patients). Among the patients examined for c-erbB-2 detection, 3 male patients $(3 / 11,27.3 \%)$ and 14 female patients $(14 / 36,38.9 \%)$ had c-erbB-2 expression. Our data corresponds with a previous study demonstrating that c-erbB-2 expression levels are lower in $\mathrm{MBC}$ patients than in FBC patients (15). Since ER/PR and c-erbB-2 predict prognosis in breast cancer $(16,17)$, we suggest that this may play a role in the difference in prognosis between our two study groups. ER/PR and c-erbB-2 status have been identified as predictive factors of response to endocrine therapy and trastuzumab treatment, respectively (16). In this study, a lower number of male patients underwent endocrine therapy (10 cases, $23.8 \%$ ) in comparison to female patients (40 cases, $47.6 \%)(\mathrm{P}=0.010)$, resulting in a lost opportunity to achieve a good outcome. We revealed that $\mathrm{MBC}$ patients had a significantly lower 5-year survival rate than FBC patients $(\mathrm{P}<0.05)$, which may be due to the different endocrine therapies used in the two groups. We suggest that this phenomenon could be overcome if doctors and patients were educated on the advantages of treating MBC and FBC patients using similar endocrine therapeutic strategies.

According to the univariate survival analysis, tumor size $(\mathrm{P}<0.05)$, lymph node involvement $(\mathrm{P}<0.05)$ and AJCC stage $(\mathrm{P}<0.05)$ were statistically significant in the 5-year DFS and OS in MBC patients. The 5- and 10-year DFS and OS rates in MBC patients were significantly lower compared to those in FBC patients $(\mathrm{P}<0.05)$. Additionally, in this study we revealed that $\mathrm{MBC}$ survivors have an increased risk of developing a 
second primary cancers other than contralateral breast cancer (10\% vs. $2.1 \%$ ). Previous studies have demonstrated that males with a history of breast cancer had a 30 - to 93 -fold greater risk of contralateral breast cancer, while FBC patients only had a 2- to 4 -fold greater risk $(18,19)$. The risk of other cancers, including melanoma and prostate cancer, may also be elevated in MBC survivors (18-22). Male breast carcinoma patients should be monitored carefully for the occurrence of second primary cancers, particularly a second primary breast cancer (23).

In general, breast cancer in males should be treated using the same strategy as used with females (24). Although the benefits of adjuvant chemotherapy and hormonal therapy have been demonstrated in a subgroup of FBC patients, the role of adjuvant chemotherapy in MBC is unclear (25). However, recent studies reported that adjuvant chemotherapy was beneficial for MBC patients (26), and may be decided by assessing the risks and benefits in the same manner as in FBC (26-29). In the present study, the proportion of MBC patients who received chemotherapy $(57.1 \%)$ was lower than FBC patients $(75.0 \%)(\mathrm{P}=0.041)$. We suggest that the differences in treatment strategies may be the most significant factors determining prognostic differences between MBC and FBC patients. We demonstrated that fewer MBC patients underwent endocrine therapy $(\mathrm{P}=0.010)$ and fewer accepted adjuvant chemotherapy $(\mathrm{P}=0.041)$ following surgery. Our results suggest that poor survival rates in MBC may be associated with the lack of adjuvant therapy in these patients. Evidence-based guidelines for adjuvant systemic therapy in FBC are rapidly implemented into community practice (30), but the same may not be true for MBC. The smaller improvement for male hazard ratios suggests a delay and/or underutilization of adjuvant therapy in males compared to females, in particular tamoxifen for hormone-positive MBC (31). Use of tamoxifen for MBC may also be limited by poor compliance due to its association with a high rate of treatment-limiting side effects in males (32), including decreased libido, weight gain, hot flashes and deep vein thrombosis.

To the best of our knowledge, this is one of the first studies of matched male and female breast cancer patients in China. It allowed the comparison of breast cancer in a homogeneous population of patients, where each male was carefully matched with two females. Limitations include the retrospective design of the study, the lack of detailed information of c-erbB-2 overexpression and the inclusion of a number of patients with unknown hormone status.

In conclusion, MBC patients had a decreased 5- and 10 -year survival when basic characteristics were matched. We propose that the difference in prognosis between MBC and FBC patients in this study was closely associated with the lack of adjuvant treatment strategies in the two groups.

\section{References}

1. Jemal A, Siegel R, Ward E, et al: Cancer statistics, 2008. CA Cancer J Clin 58: 71-96, 2008.

2. Giordano SH: Male breast cancer: it's time for evidence instead of extrapolation. Onkologie 31: 505-506, 2008.

3. Rosenblatt KA, Thomas DB, McTiernan A, et al: Breast cancer in men: aspects of familial aggregation. J Natl Cancer Inst 83: 849-854, 1991.

4. Marchal F, Salou M, Marchal C, et al: Men with breast cancer have same disease-specific and event-free survival as women. Ann Surg Oncol 16: 972-978, 2009.
5. Lynn K: Rare male breast cancer has similarities to female disease. MLO Med Lab Obs 42: 34-36, 2010.

6. Neumayer L, Schifftner TL, Henderson WG, et al: Breast cancer surgery in Veterans Affairs and selected university medical centers: results of the patient safety in surgery study. J Am Coll Surg 204: 1235-1241, 2007.

7. Anan K, Mitsuyama S, Nishihara K, et al: Breast cancer in Japanese men: does sex affect prognosis? Breast Cancer 11: 180-186, 2004

8. Shuster JJ: Median follow-up in clinical trials. J Clin Oncol 9: 191-192, 1991.

9. Kaplan EL and Meier P: Nonparametric estimation from incomplete observations. J Am Statist Assoc 53: 457-481, 1958.

10. Giordano SH, Cohen DS, Buzdar AU, et al: Breast carcinoma in men: a population-based study. Cancer 101: 51-57, 2004.

11. Joshi MG, Lee AK, Loda M, et al: Male breast carcinoma: an evaluation of prognostic factors contributing to a poorer outcome. Cancer 77: 490-498, 1996.

12. Willsher PC, Leach IH, Ellis IO, et al: A comparison outcome of male breast cancer with female breast cancer. Am J Surg 173: 185-188, 1997

13. El-Tamer MB, Komenaka IK, Troxel A, et al: Men with breast cancer have better disease-specific survival than women. Arch Surg 139: 1079-1082, 2004.

14. Anderson WF, Althuis MD, Brinton LA and Devesa SS: Is male breast cancer similar or different than female breast cancer? Breast Cancer Res Treat 83: 77-86, 2004.

15. Rudlowski C, Friedrichs N, Faridi A, et al: Her-2/neu gene amplification and protein expression in primary male breast cancer. Breast Cancer Res Treat 84: 215-223, 2004

16. Tiezzi DG, Andrade JM, Ribeiro-Silva A, et al: HER-2, p53, p21 and hormonal receptors proteins expression as predictive factors of response and prognosis in locally advanced breast cancer treated with neoadjuvant docetaxel plus epirubicin combination. BMC Cancer 7: 36, 2007.

17. Bentel JM, Birrell SN, Pichering MA, et al: Androgen receptor agonist activity of the synthetic progestin, medroxyprogesterone acetate, in human breast cancer cells. Mol Cell Endocrinol 154: $11-20,1999$

18. Auvinen A, Curtis RE and Ron E: Risk of subsequent cancer following breast cancer in men. J Natl Cancer Inst 94: 1330-1332, 2002.

19. Dong $\mathrm{C}$ and Hemminki K: Second primary breast cancer in men. Breast Cancer Res Treat 66: 171-172, 2001.

20. Hodgson NC, Button JH, Franceschi D, et al: Male breast cancer: is the incidence increasing? Ann Surg Oncol 11: 751-755, 2004.

21. Hemminki K, Scelo G, Boffetta P, et al: Sencond primary malignancies in patients with male breast cancer. Br J Cancer 92: 1288-1292, 2005 .

22. Leibowitz SB, Garber JE, Fox EA, et al: Male patients with diagnoses of both breast cancer and prostate cancer. Breast J 9: 208-212, 2003.

23. Satram-Hoang S, Ziogas A and Anton-Culver H: Risk of second primary cancer in men with breast cancer. Breast Cancer Res 9: R10, 2007.

24. National Comprehensive Cancer Network: NCCN practice guidelines in oncology 2009. Available from: http://www.nccn.org/professionals/physician_gls/f_guidelines.asp. Accessed 30 May, 2010.

25. Giordano SH, Buzdar AU and Hortobagyi GN: Breast cancer in men. Ann Intern Med 137: 678-687, 2002.

26. Giordano SH, Perkins GH, Broglio K, et al: Adjuvant systemic therapy for male breast carcinoma. Cancer 104: 2359-2364, 2005.

27. Agrawal A, Ayantunde AA, Rampaul R and Robertson JF: Male breast cancer: a review of clinical management. Breast Cancer Res Treat 103: 11-21, 2007.

28. Nahleh $\mathrm{Z}$ and Girnius S: Male breast cancer: a gender issue. Nat Clin Pract Oncol 3: 428-437, 2006.

29. Fentiman IS, Fourquet A and Hortobagyi GN: Male breast cancer. Lancet 367: 595-604, 2006.

30. Mariotto A, Feuer EJ, Harlan LC, et al: Trends in use of adjuvant multi-agent chemotherapy and tamoxifen for breast cancer in the United States: 1975-1999. J Natl Cancer Inst 94: 1626-1634, 2003.

31. Ribeiro $G$ and Swindell R: Adjuvant tamoxifen for male breast cancer (MBC). Br J Cancer 65: 252-254, 1992.

32. Anelli TF, Anelli A, Tran KN, et al: Tamoxifen administration is associated with a high rate of treatment-limiting symptoms in male breast cancer patients. Cancer 74: 74-77, 1994. 